\title{
TURKEY BREAST MEAT DEVELOPMENT AND MAXIMISING THE GENETIC POTENTIAL
}

\author{
Jérôme Noirault \\ Aviagen Turkeys Ltd, Cheshire, UK \\ E-mail: j.noirault@aviagen.com
}

\begin{abstract}
Breast Meat is the most lucrative part of the turkey carcass contributing to $70 \%$ of the profit whilst only representing $23-26 \%$ of the liveweight. Thus breast meat is the most sought after genetic trait in the poultry industry with the aim to maximise breast meat per bird in percentage of the carcass. Before assessing Breast meat yield (BMY) and its deposition it is necessary to look at muscle development.
\end{abstract}

\section{KEY WORDS}

Meat, turkey, genetic potential, research.

Breast muscle development is divided into two phases: prehatch and posthatch period

Figure 1). During the prehatch period (hyperplasia), embryonic muscle growth is achieved by increase and differentiation of myoblasts which then merge to form muscle fibre. Muscle fibre formation is almost completed at hatch. (Smith, 1963), the number of muscle fibres remains constant thereafter.

Posthatch period of muscle growth is mediated through activation, proliferation and differentiation of the additional Satellite cells, which stimulates the thickening of the muscle fibres (hypertrophy).

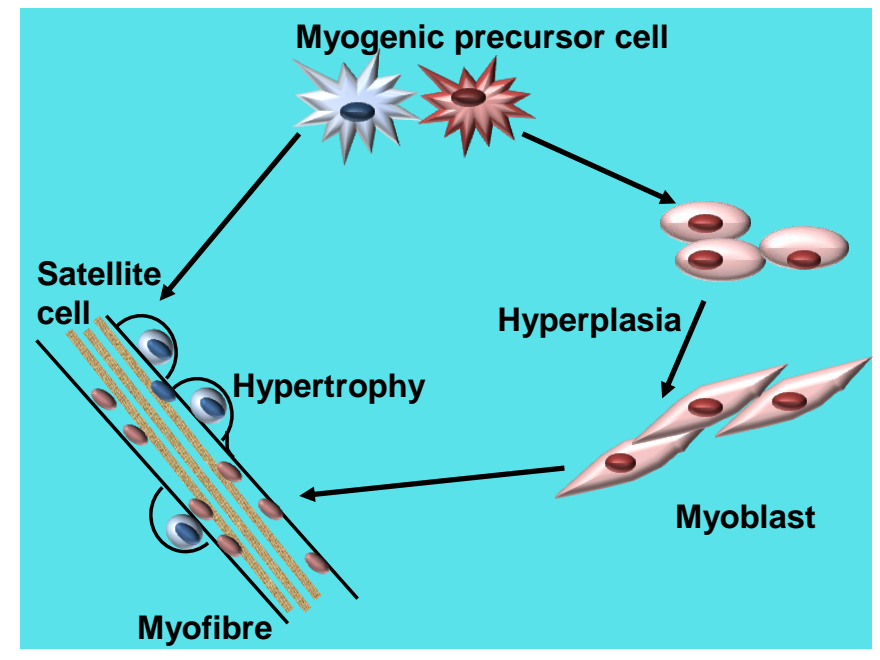

Figure 1 - Myofibre development, courtesy of Dr. Velleman

Embryonic growth does not always consist of all the myoblasts forming myotubes. This is due to some of the myotubes becoming satellite cells which lie inactive around muscle fibre edges.

The growth and repair of muscle fibres is important with support from the nuclear material. This is contributed when the birds have hatched and the satellite cells (Figure 2) are activated within the muscle. Protein is key for the growth of muscle fibres, which can be achieved when combining the satellite cells with the muscle fibres. 


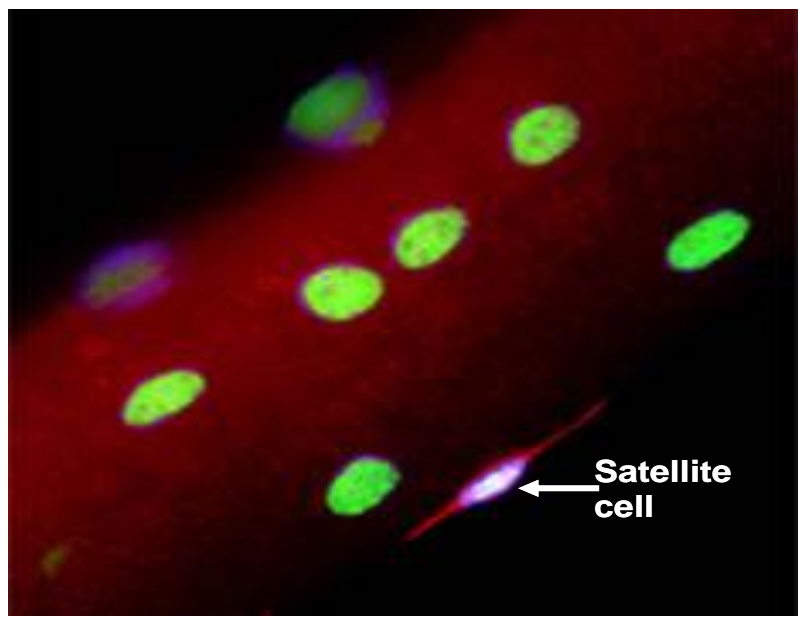

Figure 2 - Satellite cell on myofibre, Terry Partridge, Muscle Cell Biology

What is breast muscle? Breast muscle is made up of a set of arranged sets of juxtaposed parallel fibres, surrounded by the vascularised connective tissue. Each set of muscle fibre sets has a perimeter of a finer connective tissue, known as the perimysium. This supports a vascular network surrounding other nervous elements within the muscle. The perimysium then has an extension, made up of a connective tissue called the endomysium, which surrounds each muscle fibre.

The Pectoralis major muscle consists of white muscle fibres responsible for movement and locomotion, having limited access to $\mathrm{O}_{2}$, due to less blood vascularisation.

The breast fibres are 99.8\% Fast Twitch Glycolytic, type IIB (FTG, Lengerken et al., 2002) in order to produce energy in those anaerobic conditions in response to stress.

Muscle fibres are an important role to the breast muscle, the number and size of the fibres is vital. Removal of by-products, such as lactic acid depends on the connective tissue and the fat infiltration between the sets of muscle fibres. The knowledge of muscle characteristics helps develop and understand the progress for the right muscle structure.

The information Aviagen Turkeys has researched and studied to create the right breast development and muscle structure is based on 5 criteria: 1 Fibre Uniformity, 2 Immune Cell Infiltration, 3 Perimysial Fat Bundle, 4 Endomysial Fat Bundle, 5 Epimysial Spacing (Fig. 3).

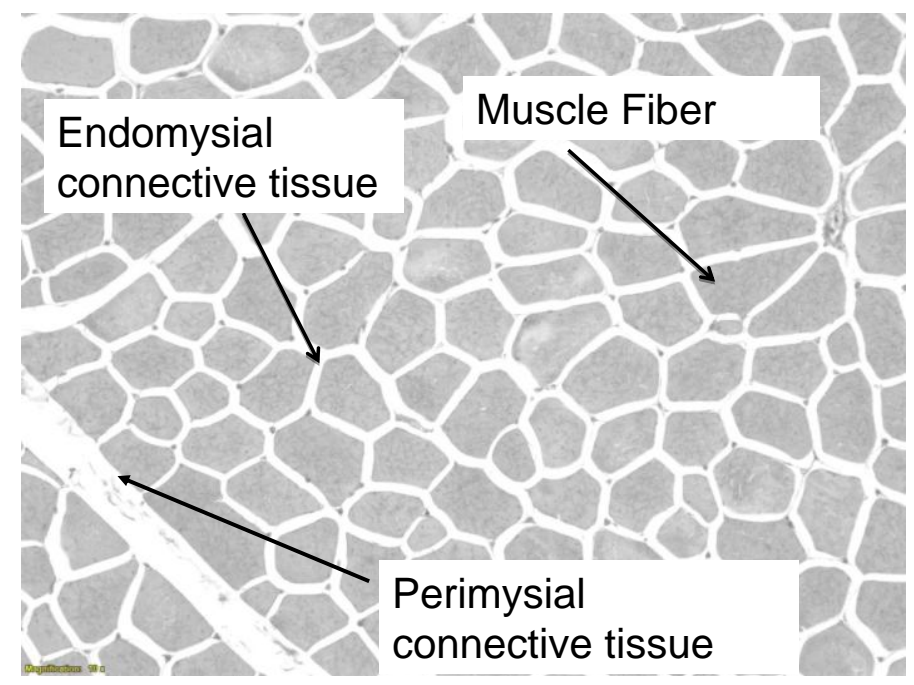

Figure 3 - Cross section of muscle tissue

The breast muscle of the modern turkey has been selected for increased size. Comparing the BUT6 and free range type birds has shown no deterioration or giant fibres 
(Werner et al., 2008). This was looked into due to the muscle fibre size possibly causing increased risk of necrotic fibres and reduced perimysial and endomysial space.

Breast meat yield assessment. The methodology in measuring the BMY depends on the plant set-up, the staff available and the area of work. Comparisons with this type of method are structural with the help from a standardised protocol. The BMY percentage is measured on a portion of the live weight, not just carcass weight.

The birds were selected from a flock average, having separate work stations for the team to do the cutting. The breast meat measurements $M$. pectoralis superficialis and the $M$. pectoralis profundus without the shoulder and with all skin removed is used to accumulate a percentage of the liveweight of the turkey before processing.

Typically the BMY potential improvement since the last 10 years and for the following one is close to $1.6 \%$ (Figure 4 from Aviagen Turkeys).

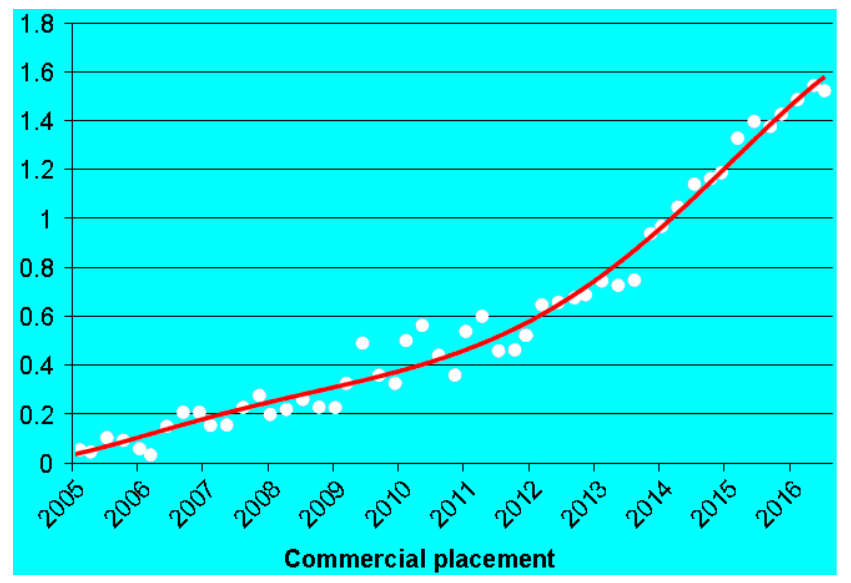

Figure 4 - Breast Meat Yield potential over the last 10 years

Maximising genetic potential. A combination of number of fibres, number of satellite cells active (Mozdziak et al., 1994) and available, for protein synthesis and the rate of protein turnover; influence the muscle growth. The muscle fibre size is found after hatch, resulted from the total of DNA gained (Velleman, 2007). This is found from the fusion of satellite cells, the rate of muscle deposition, which is determined from the rate of protein turnover in the muscle.

From phenotypic selection research, between commercial and traditional turkey genotypes, the outcome found, there is an advance on the weight and meat yield due to having progress with post-hatch muscle growth (hypertrophy as shown by the increase in fibre diameter, Figure 5, Gatcliffe, ATL technical article). Results were also found regarding the breast meat mass, discovering bigger fibre diameter per $\mathrm{kg}$ of breast in the traditional turkey strain (Figure 6, Gatcliffe ATL technical article).

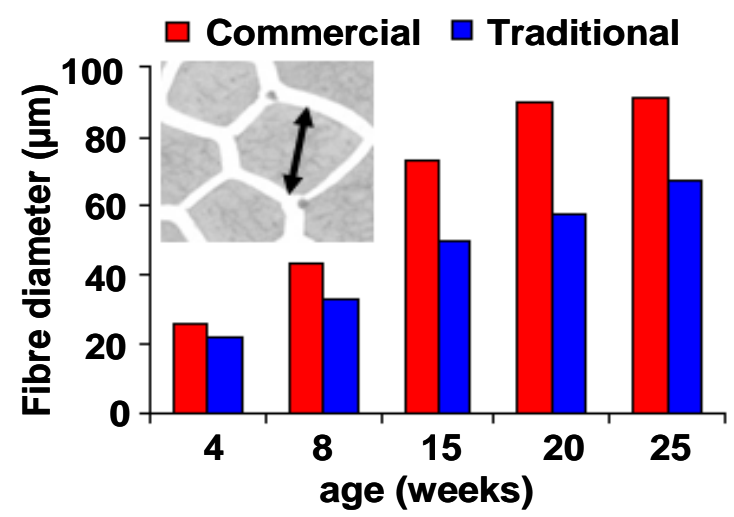

Figure 5 - Measurement of muscle fibre diameter as an indication of hypertrophy during muscle growth 


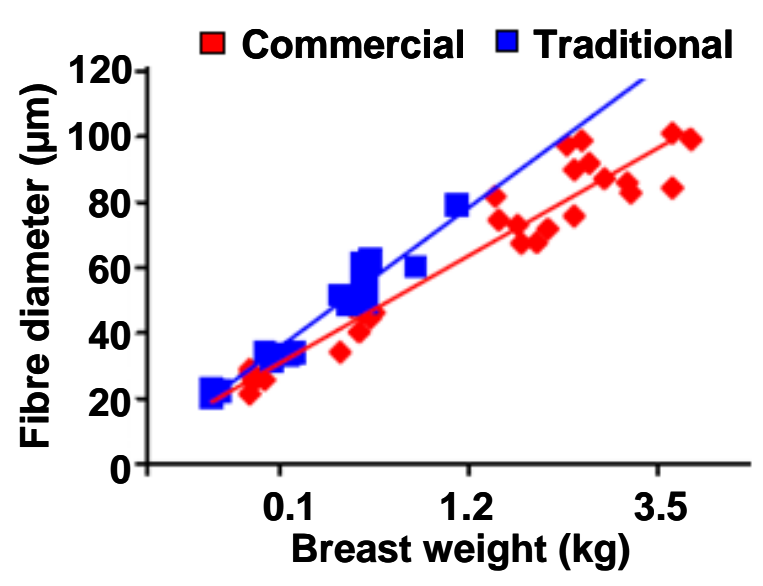

Figure 6 - Fibre diameter per $\mathrm{kg}$ of breast muscle

Primary breeders would be advised to look at genotype $X$ environmental features which will influence the progress of the muscle, including the structure growth and muscle fibres.

Influencing factors. The growing cycle of a traditional turkey consists of different stages. In stage two there are many factors taking part in the growth and muscle development of the deposition of breast meat, these are shown in Figure 7.

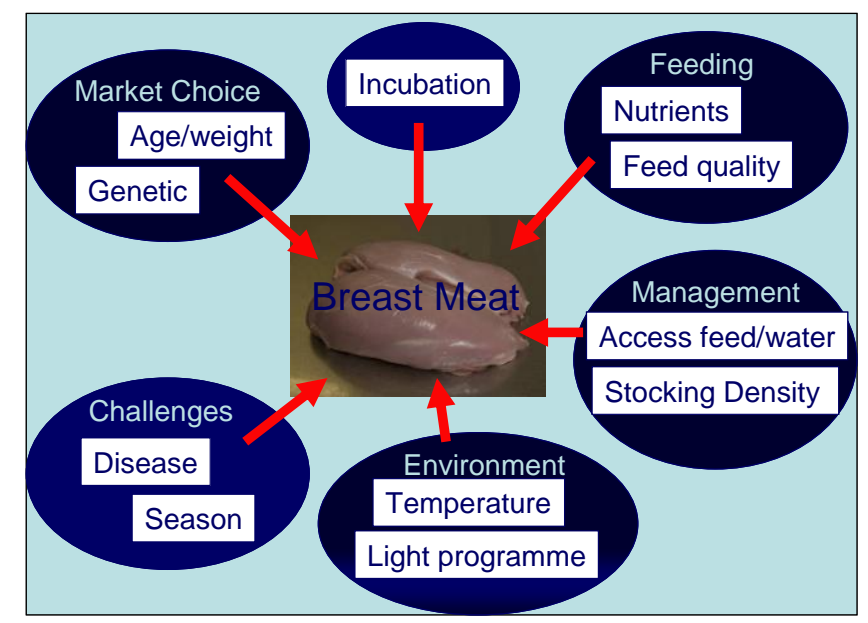

Figure 7 - Factors affecting Breast Meat Yield

Many aspects for the finest breast meat yield can be simple to achieve, assuming the choice of breed is matched with the correct killing age, which will depend on the customer satisfaction. The turkeys should also be free from disease which could cause effect to their fitness and focus. The environmental and rearing factors should also be considered, as this can influence the development and growth of the breast meat yield.

Incubation. If incubation temperatures were to be increased $\left(+1^{\circ} \mathrm{C}\right)$ during the first stages of incubation, it can be possible to influence the muscle fibre numbers and the number of myonuclei, (Maltby et al., 2004; Somaiya 2004, in collaboration with Aviagen Turkeys). Towards the end of the incubation stage, the muscle fibres will still be increasing and depending on if there has been high temperatures and low oxygen, this can have an effect on the diameter of the breast fibres (Christensen et al., 2007). This is why it is important to adapt the incubation programme to the breed type.

Nutrition and feed effects. Regarding the chicks and poults nutrition, it has been found that offering nutrients straight after hatch will improve their body weight and BMY (Noy and Sklan, 1999). Therefore if this procedure was not considered and feed deprivation occurred, this can have a negative impact on the satellite cell proliferation, and decrease in muscle 
weight later in life (Vieira and Moran 1999; Halevy, et al., 2000; Mozdziak et al., 2002; Moore, 2005).

The feeding procedure for Turkeys has to be kept in a consistent format. They do adapt quickly to feeding regimes, however they may react badly to the variation, amount or quality of the feed. This is important to consider as it can influence to development and growth of the breast meat. The feed needs to be easily presented and the quality needs to be fresh and easily digestible for the Turkey to retrieve the nutrients and absorb into its body, to convert into tissue.

Physical environment. There are many factors to consider when producing turkeys to the highest standards. These include having the best access to feed, controlling the stock density and the feeding space they have available. Sticking to these limits allows the turkeys to express their genetic potential they need to be grown in their environment. Lighting is also a key issue, which should include a period of 6-8 hours of darkness (Halvorson et al., 1991; Clarke et al., 1993).

The thermoneutral zone for turkeys is a high importance which can be monitored by controlling the temperature and ventilation within the environment. Controlling this will reduce any energy waste from the feed to maintain their thermoneutral and stimulate their feed consumption. The control of the physical environment can have a big difference to the BMY ranging from $1-2 \%$ between seasons (see figure 8 ). .

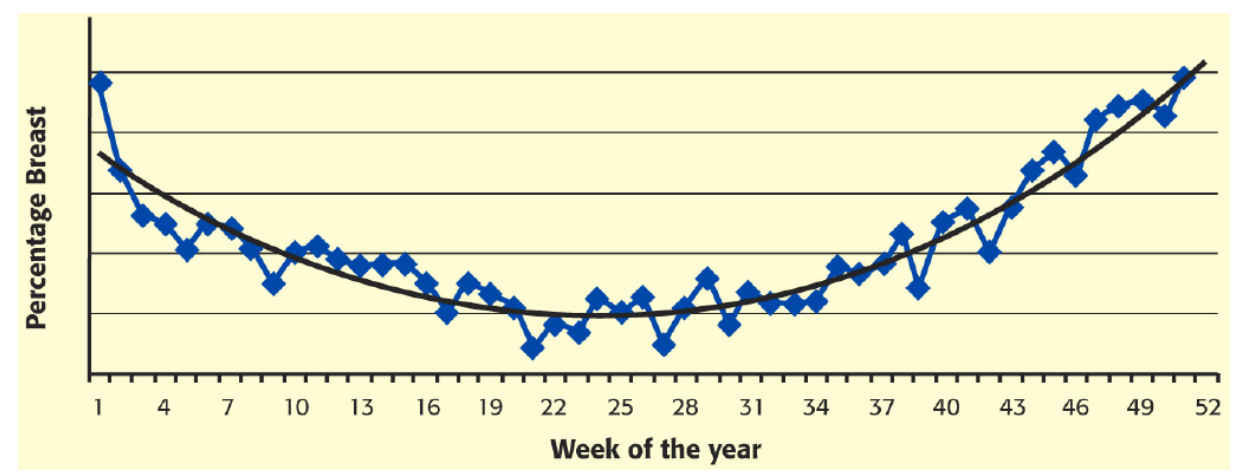

Figure 8 - Breast meat yield during the year

\section{CONCLUSION}

Focus should be on the interest of maximising meat yield on individual birds, in order to stay competitive with other animal proteins. A combination of breeds with a higher meat yield potential, good quality feed and knowledgeable on farm management can maximise breast meat output and profitability. To support the turkey industry breeding operations should focus on the latter.

\section{REFERENCES}

1. Christensen VL, Wineland MJ, Grimes JL, Oviedo EO, Mozdziak PS, Ort DT, Mann KM (2007) Effect of incubator temperature and oxygen concentration at the plateau stage in oxygen consumption on turkey embryo muscle growth and development. Inter. J. Poultry Sci. 6 (6):406-412.

2. Clarke JP, Ferket PR, Elkin RG, McDaniel CD, Freed M, McMurtry JP, Krueger KK, Hester PY (1993) Early dietary protein restriction and intermittent lighting. 2. Effects on carcass characteristics of male turkeys. Poultry Sci. 72:2144-2151.

3. Gatcliffe J (2004). Influencing turkey muscle structure and growth. Aviagen Turkey LTD technical article.

4. Halevy O, Geyra A, Barak M, Uni Z, Sklan D (2000). Early posthatch starvation decreases satellite cell proliferation and skeletal muscle growth in chicks. J. Nutr. 130:858-864. 
5. Halvorson JC, Waibel PE, Oju EM, Noll SL, El-Halawani M (1991) Effect of diet and population density on male turkeys under various environmental conditions. 2. Body composition and meat yield. Poultry Sci.70:935-940.

6. Huxley HE, (1969) The Mechanism of Muscular Contraction. [Review] Science. 164:1356-1365.

7. Noy Y, Sklan D (1999) Different types of early feeding and performance in chicks and poults. J. Appl. Poult. Res. 8:16-24.

8. Maltby V, Somaiya A, French NA, Stickland NC. (2004) In ovo temperature manipulation influences post-hatch muscle growth in the turkey. Br Poultry Sci. 45:491-498.

9. Moore DT (2005) The influence of early nutrition on muscle development in the poult. Ph.D. Dissertation. North Carolina State University. Raleigh, NC

10. Mozdziak PE, Schultz E, Cassens RG (1994) Satellite cell mitotic activity in posthatch turkey skeletal muscle growth. Poultry Sci. 73:547-555.

11. Mozdziak PE, Walsh TJ, Mccoy DW (2002) The effect of early post-hatch nutrition on satellite cell mitotic activity. Poultry Sci. 81:1703-1708.

12. Murawska, D. (2013) Age-related changes in the percentage content of edible and nonedible components in turkeys. Poultry Sci. 92:255-264

13. Nierobisz LS (2010) Molecular Mechanisms Characterizing Skeletal Muscle Phenotype and Functionby, Ph.D., North Carolina; 3442685

14. Powell DJ, McFarland DC, Cowieson AJ, Muir WI, Velleman SG (2014). The effect of nutritional status and muscle fiber type on myogenic satellite cell fate and apoptosis. Poultry Sci. 93(1):163-73.

15. Smith JH (1963) Relation of Body Size to Muscle Cell Size and Number in the Chicken. Poultry Sci. 42:283-290.

16. Somaiya A (2004) In ovo temperature manipulation of the turkey embryo. Thesis. The Royal Veterinary College, University of London, London, NW1 OTU, UK.

17. Velleman SG (2007) Muscle development in the embryo and hatchling. Poultry Sci.86:1050-1054.

18. Vieira SL, Moran ET (1999) Effects of egg origin and chick post-hatch nutrition on broiler live performance and meat yields. World's Poult. Sci. J. 55:125-142.

19. von Lengerken GV, Maak S, Wicke M (2002) Muscle Metabolism and meat quality of Pigs and Poultry. Veterinarija Ir Zootechnika. 20:82-86.

20.Werner C, Riegel J, Wicke M, (2008) Slaughter Performance of Four Different Turkey Strains, with Special Focus on the Muscle Fiber Structure and the Meat Quality of the Breast Muscle. Poultry Sci. 87:1849-1859 